\title{
Central Cellular Mechanisms Underlying Temperature- Dependent Changes in the Goldfish Startle-Escape Behavior
}

\author{
Thomas Preuss and Donald S. Faber \\ Albert Einstein College of Medicine, Department of Neuroscience, New York, New York 10461
}

\begin{abstract}
Activation of auditory afferents on the lateral dendrite of the Mauthner (M)-cell triggers an escape response (C-start) in goldfish. To study distinct behavioral changes and their physiological correlates on a cellular level we examined the effect of acute changes of temperature on M-cell membrane properties and intracellular responses to sound clicks and on C-start kinematics and behavior, focusing on threshold and initial escape direction, two properties determined on the M-cell level. Cooling slowed C-start motor performance, increasing response latency and decreasing peak velocity and peak acceleration, but increased the probability of triggering the escape. In addition, the likelihood of escapes in an inappropriate direction (e.g., responses toward the stimulus instead of away from it) increased at low temperatures. On a cellular level, cooling caused a distinct increase in input resistance of the M-cell and in the dendritic space constant for the auditory-evoked synaptic potentials. Moreover, cooling decreased the magnitude and delayed the onset of feedforward inhibition of the M-cell. These temperature-induced changes in the network and in the intrinsic M-cell properties combine to support behavioral hyperexcitability, but apparently also alter the directional decision-making process during an escape. More generally, our results illustrate that the balance between excitatory and inhibitory influences can determine the expression of a behavior and its modification and at the same time underline the significance of temperature for nervous system function and behavior.
\end{abstract}

Key words: dendritic cable properties; auditory-evoked response; excitatory/inhibitory balance; kinematics; neural temperature effects; escape behavior; neuroethology; Mauthner cell

\section{Introduction}

One fundamental issue in neuroscience is to understand the neural basis of naturally occurring behaviors; this can be approached by perturbing a system that is accessible for both cellular and behavioral investigations. Then, it may be possible to draw general conclusions from the changes observed at these levels. Poikilotherms, that is, cold-blooded animals, are well suited for such studies because they have the task of maintaining coordinated sensorimotor function in the face of continual changes in temperature, which are known to influence both nervous system function and behavior. More specifically, it is established that a wide range of aquatic species are subjected to acute temperature changes that can be as great as $15^{\circ} \mathrm{C}$ over only a few minutes (Montgomery and MacDonald, 1990). The present study was designed to quantify the effects of acute temperature changes on the teleost startle response to extract central cellular and synaptic mechanisms critical to the proper execution of this behavior.

The teleost C-start is a prominent startle response to sudden visual or mechanosensory stimuli (Eaton and Hackett, 1984), considered to be important for predator avoidance (Eaton et al., 1977; Webb 1978a, 1986; for review, see Domenici and Blake,

\footnotetext{
Received March 4, 2003; revised April 7, 2003; accepted April 9, 2003

This work was supported by National Institutes of Health Grant NS 15335. We thank Princess E. Osei-Bonsu for excellent technical assistance with the behavioral experiments, Kamran Khodakhah and Alberto Pereda for comments on this manuscript, and Haftan Eckholdt for help with the statistical analysis.

Correspondence should be addressed to Dr. Thomas Preuss, Department of Neuroscience, Albert Einstein College of Medicine of Yeshiva University, 1300 Morris Park Avenue, Bronx, NY 10461.E-mail: tpreuss@aecom.yu.edu Copyright $\odot 2003$ Society for Neuroscience $\quad$ 0270-6474/03/235617-10\$15.00/0
}

1997). C-starts are controlled by a brainstem escape network that includes two large reticulospinal Mauthner neurons (M-cells) and their associated networks (Faber et al., 1989), which have been the subject of numerous neurophysiological (Furshpan and Furukawa, 1962; Furukawa and Furshpan, 1963; Faber and Korn, 1978; Korn et al., 1990; Faber et al., 1991; Zottoli and Faber, 2000) and neuroethological (Eaton and Hackett, 1984; Eaton, 1991; Eaton et al., 1981, 1991, 2001) studies. Essentially, an action potential in one M-cell activates contralateral motor execution networks that cause an initial fast body bend (C-start) away from an aversive stimulus (Zottoli, 1977; Eaton et al., 1981). Thus, activity in the left or right $\mathrm{M}$-cell determines the initial escape direction and execution, whereas the subsequent parts of the escape are apparently controlled by other descending brainstem neurons (Fetcho, 1991; Foreman and Eaton, 1993). Escape success depends largely on the motor performance during C-starts, on behavioral responsiveness (i.e., on response threshold) (Webb 1981, 1986; Blaxter and Fuiman, 1990; Webb and Zhang, 1994), and on the control of its directionality (Eaton et al., 2001), features that may be sensitive to changes in ambient temperature (Webb, 1978b; Webb and Zhang, 1994; for review, see Temple and Johnston, 1997). Although changes in the kinetic properties of the neuromuscular system may account for the thermal dependence of swimming performance (Bennett, 1985, 1990; Johnson et al., 1998), the effect of temperature on behavioral responsiveness is likely to be attributable to cellular and synaptic factors that determine M-cell excitability, including the temperature sensitivity of the sensory pathway (Fay and Ream, 1992). Indeed, our 
findings indicate that an increased behavioral responsiveness and a decreased directional selectivity during acute cold exposure can be correlated to changes in the two mechanisms that control $\mathrm{M}$-cell activation, namely its dendritic cable properties and the balance between synaptic excitation and inhibition.

\section{Materials and Methods}

Goldfish (Carassius auratus), $10-13 \mathrm{~cm}$ in body length, were obtained commercially between May and October 2001 (Hunting Creek Fisheries, Thurmont, MD) and maintained in groups of 10-15 animals in a 1201 recirculating system of de-ionized water conditioned with NovAqua ( 0.13 ml/l; Novalek, Hayward, CA), Instant Ocean (16 mg/l; Aquarium Systems, Mentor, OH), Copper Safe (0.32 ml/l; St. John Laboratories, Harbor City, CA) at $18^{\circ} \mathrm{C}$ on a $12 \mathrm{hr}$ light/dark photoperiod. Water quality was monitored regularly and was the same for holding and experimental tanks ( $\mathrm{pH} 7 \pm 0.2$; dissolved oxygen saturated, $8 \mathrm{ppm}$ ). Fish were allowed to acclimate for at least 3 weeks before use.

Behavioral experiments. A total of 39 animals were used to study the effect of acute temperature exposure on the escape behavior. Individual groups of three fish were transferred from the holding tank to an experimental tank that contained either water at the acclimation temperature $\left(18^{\circ} \mathrm{C}\right)$ or cold $\left(8^{\circ} \mathrm{C}\right)$ water and were allowed to adapt for $30 \mathrm{~min}$ before testing. Thus, three fish were tested together for each trial. We chose to use three fish in the arena rather than an isolated one, as had been done in previous studies (Oda et al., 1998; Zottoli et al., 1999), because it allowed us to collect extensive data on behavioral responsiveness, including its dependence on stimulus intensity. This modification was possible because the experimental tank is significantly larger than that used in previous studies of this behavior. The larger tank allows most escapes to occur in an open field that is at least two to three body lengths square, thereby reducing the effects of any nearby obstructions (Eaton and Emberley, 1991). Because isolated fish quickly learn to avoid the center of the arena, using three fish is favored. As described below, the results are consistent with the notion that the three fish respond independently. After the conclusion of 15-20 escape trials at a given temperature, the water temperature was raised to $18^{\circ} \mathrm{C}$ or lowered to $8^{\circ} \mathrm{C}$, as appropriate, with the fish remaining in the tank, and then another 15-20 escape trials followed. The starting temperature alternated from one group to the next. The more rapid temperature change experienced by the fish exposed first to cooling, compared with those cooled after being first studied in the warm, had no obvious effect on their response frequencies.

The experimental setup consisted of a circular acrylic tank $(76 \mathrm{~cm}$ diameter, $28 \mathrm{~cm}$ water depth) connected to a water reservoir attached to a chiller (Delta Star; Aqua Logic, San Diego, CA), which changed the water temperature in the experimental tank from 18 to $8^{\circ} \mathrm{C}$ in $\sim 50 \mathrm{~min}$. Temperature was returned to $18^{\circ} \mathrm{C}$ at a similar rate by two $200 \mathrm{~W}$ water heaters. The water temperature in the tank was continuously monitored and regulated to $\pm 1^{\circ} \mathrm{C}$ by a digital temperature controller (Nema Type $4 \mathrm{x}$; Aqua Logic). To eliminate external mechanosensory and visual cues, the tank was on an antivibration table (TMC 63-530; Technical Manufacturing Corp., Peabody, MA) and had surrounding opaque covers. Illumination was provided through a $3 \mathrm{~mm}$ thick translucent tank cover by a single $100 \mathrm{~W}$ floodlight centered above the tank and from below with three $40 \mathrm{~W}$ lights with translucent covers. The inner side walls of the tank were lined with $6 \mathrm{~cm}$ thick and $26 \mathrm{~cm}$ high polyurethane foam, which served to support an underwater loudspeaker (UW-30; University Sound, Buchanan, MI) for sound stimulation. Short-latency C-start escapes were elicited with sound clicks consisting of a single sine wave of $200 \mathrm{~Hz}$ produced by a digital waveform generator (Model 39; Wavetek Ltd, Norfolk, UK) in combination with an audio power amplifier (Servo 120; Samson, Syosset, NY). The stimulus amplitude and the time intervals between trials were varied randomly, from 130 to $170 \mathrm{~dB}$ sound reference level $1 \mu \mathrm{Pa}$ (which translates to $\sim 60-110 \mathrm{~dB}$ in air) and 2-20 $\mathrm{min}$, respectively. Ventral views of the animals were recorded at 1000 frames/sec and at a spatial resolution of 512 by 384 pixels through a mirror at $45^{\circ}$ below the tank, using two high-speed video cameras (Kodak Extapro 1000 HRC; Eastman Kodak, San Diego, CA), and stored on an internal magneto-optical drive. The field of view of one camera,
A
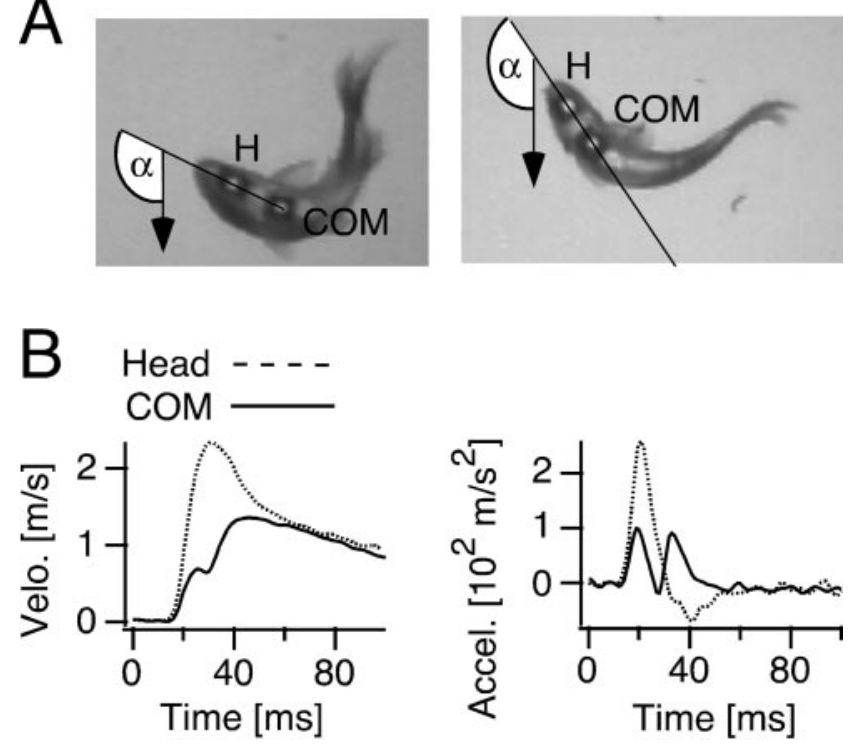

Figure 1. Measurements of C-start kinematics. $A$, Video pictures of two goldfish with markers attached filmed from below. The $x$ - and $y$-positions of the head $(\mathrm{H})$ and the $\mathrm{COM}$ were measured, as well as the angle $\alpha$ of the orientation of the fish's head, defined by the intersection of the line connecting the two markers with an axis originating at the loudspeaker (arrow). $\alpha=0^{\circ}$ with the animal facing the underwater loudspeaker. The images were captured during C-starts in the warm $\left(18^{\circ} \mathrm{C}\right.$; left) and in the cold $\left(8^{\circ} \mathrm{C}\right.$; right), $38 \mathrm{msec}$ and $57 \mathrm{msec}$ after a sound click, respectively. $B$, Kinematics of a $C$-start. Plots of the time course of velocity, and acceleration obtained from a single response at $18^{\circ} \mathrm{C}$ with separate measurements for head (dashed line) and COM (solid line).

equipped with a $8.5 \mathrm{~mm}$ wide-angle lens, covered the entire tank area, to record the escape behavior of all three animals simultaneously for determining escape probabilities and trajectories. The second camera was equipped with a $50 \mathrm{~mm}$ lens and recorded a magnified view of a $32 \times 25$ $\mathrm{cm}$ area in the middle of the tank (see Fig. 5). Typically, the experimenter waited until at least one fish was in this zone before activating the stimulus. This procedure allowed recording C-starts, with high resolution, of fish that had an unobstructed escape path (i.e., at least a body-length distance from the border of the aquarium). In general, the behavior was also not impeded by neighboring fish, because the separation between fish in these experiments was greater than one body length in $83 \%$ of the cases. A 1 msec light-emitting diode-stimulus marker added to the optical path outside the tank and not seen by the fish indicated the stimulus onset and served as a reference point for latency measurements. In addition, the waveform and amplitude of the auditory stimulus was recorded (sampling rate, $30 \mu \mathrm{sec}$ ) with two hydrophones (SQ05; Sensor Technology, Collingwood, Ontario, Canada), one positioned close to the underwater speaker and the other on the opposite border. A series of hydrophone recordings from various midwater positions in the tank revealed an approximate radial intensity gradient of the sound field with a maximum at the position of the underwater loudspeaker.

$\mathrm{C}$-start kinematics and latency were analyzed at 1000 frames/sec. For each escape sequence, 180 frames (starting 10 frames before the stimulus) were digitized and the $x$ - and $y$-positions of the head and the center of mass $(\mathrm{COM})$ were measured using video-image tracking software (WINanalyze; Micromak, Erlangen, Germany). To facilitate detection, two markers were glued to the ventral midline in some fish, one close to the tip of the head and the other at the approximate position of the animals' center of mass (Fig. 1), which is roughly defined as the midline point approximately one-third of the body length from the rostral end of the animal. The body-length-specific instantaneous velocity (body lengths/sec) and acceleration of the COM, and the total distance traveled by the COM at various time intervals (i.e., 100 and $150 \mathrm{msec}$ after stimulus onset, and $100 \mathrm{msec}$ after onset of the behavioral response) were calculated from smoothed (10 factor binomial; Igor Pro; WaveMetrics, Lake Oswego, OR) $x$-, $y$-position data. In addition, the angle between the 
orientation of the fish and the speaker (Fig. 1) and the angular velocity and acceleration were calculated for successive frames. Response latency was defined as the first detectable movement of the head after the stimulus and was measured manually in successive video images of marked and unmarked fish. When more than one fish responded in a given trial $(<20 \%$ of the analyzed escapes), only the measurement from the fish that responded first was used for kinematic analysis. The relative frequency of C-starts was calculated from individual experimental trials with three animals each, and when more than one fish responded, only those $\mathrm{C}$-starts that began within $2 \mathrm{msec}$ after the onset of the first response in the warm $\left(18^{\circ} \mathrm{C}\right)$ or $4 \mathrm{msec}$ in the cold $\left(8^{\circ} \mathrm{C}\right)$ were scored, eliminating responses that might have been triggered by movements of the first fish to react. These time windows, which are quite restrictive, were based on our physiological measurements of sensory and M-cell processing times at the two temperatures (see Table 1). For all kinematic measurements, restricted to marked fish, the mean \pm SE was calculated, with $N$ equal to the number of animals and $n$ to the number of escapes analyzed. In contrast, measurements of latencies ( $n=$ number of escapes) and response frequencies ( $n=$ total number of trials) included unmarked fish and had larger sample sizes

Electrophysiological recordings. A total of 19 goldfish were used to study in vivo effects of acute temperature exposure on the electrical and synaptic properties of the $\mathrm{M}$-cell. The temperature in these experiments was initially $8^{\circ} \mathrm{C}$ (measured in the brain), and it was subsequently raised to $18^{\circ} \mathrm{C}$ within a $30 \mathrm{~min}$ period. The temperature was measured with a 33-gauge hypodermic thermocouple probe (HYP-0; Omega, Stamford, CT) inserted into the medulla oblongata. Brain temperature was changed by varying the temperature of the water used to aerate the gills and was kept within a range of $\pm 1^{\circ} \mathrm{C}$ by using a cooling/heating system similar to that described for the behavioral experiments. The saline used to superfuse the brain was kept at the same temperature as the respiration water by using a constant-temperature funnel (Aldrich, Milwaukee, WI) connected to the cooling system. The fish were anesthetized initially using ice-cold water and throughout the experiment by flowing aerated, conditioned tap water containing anesthetic $(70 \mathrm{mg} / \mathrm{l} 3$-aminobenzoic acid ethyl ester; Sigma, St. Louis, MO) through the gills; they were immobilized with D-tubocurarine ( $1 \mathrm{mg} / \mathrm{g}$ of body weight) injected intramuscularly. The surgical and recording procedures were similar to those described previously (Faber and Korn, 1978).

Intracellular responses to sound and antidromic stimulation were recorded from various positions (50-400 $\mu \mathrm{m}$ from the axon cap; i.e., the initial segment and axon hillock region of the $\mathrm{M}$-axon) along the $\mathrm{M}$-cell lateral dendrite and from the soma, with electrodes (7-10 M $\Omega$ ) filled with $5 \mathrm{~m} \mathrm{~K}$-acetate. Recordings were made either with a single electrode in up to seven successive penetrations or with two electrodes simultaneously. All recordings were in current-clamp, and cross talk between the electrodes was minimized electronically with an Axoprobe-1A amplifier (Axon Instruments, Foster City, CA). Data were recorded online with a Macintosh G4, using acquisition software developed in the laboratory (sampling rate, $10-30 \mu \mathrm{sec}$ ) and analyzed with the same software and with Igor Pro. Sound-evoked PSPs were elicited by single sine waves of $200-700 \mathrm{~Hz}$ and $66-84 \mathrm{~dB}$ in air produced by the waveform generator in combination with two speakers, one on each side of the fish and slightly above it. The loudspeakers, with integrated amplifiers, were each $60 \mathrm{~cm}$ from the animals' heads. The sound stimulus was recorded with a microphone positioned above the fish, stored online together with the electrical recordings, and calibrated with a sound-level meter (72-860; Tenma, Springboro, $\mathrm{OH})$. For antidromic stimulation of the M-cell a bipolar electrode (SS 2C TW; Plastics One, Roanoke, VA) was placed on the exposed spinal cord near the posterior end of the dorsal fin.

Statistical analysis. Data were analyzed using a statistical software package (SAS 8.1; SAS Institute, Cary, NC). Hypotheses about fish kinematics were assessed with a mixed-models repeated-measures ANOVA. In general, the same approach was used to test hypotheses related to data on M-cell physiology, unless the study design required a $t$ test, as noted in Results. Hypotheses concerning the distribution of escape behavior, in which fish triplets were the unit of analysis, were assessed by applying a goodness-of-fit test to the binomial distribution (Morel and Neerchel, 1998).

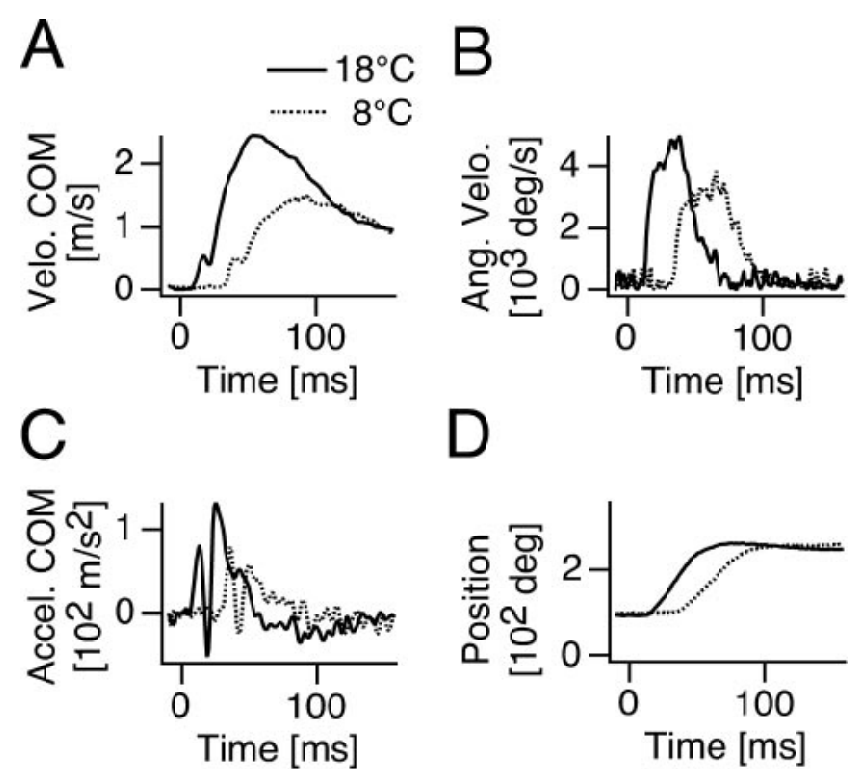

Figure 2. Effects of cooling on kinematics of (-start escape. Plots of COM velocity $(A)$, angular velocity $(B)$, COM acceleration $(C)$, and animal orientation $\alpha(D)$ versus time for $C$-starts evoked at $18^{\circ} \mathrm{C}$ (solid lines) and $8^{\circ} \mathrm{C}$ (dotted lines), respectively. Note that cooling slows motor performance.

\section{Results}

\section{Effects of cooling on escape behavior}

Sound-evoked, short-latency escapes in goldfish are characterized by an initial C-shaped bend of the animal head and tail around the COM (Fig. 1A), followed by a return flip of the tail associated with forward propulsion (stages 1 and 2 in Foreman and Eaton, 1993). The C-bend formation was typically correlated with a distinct increase in head velocity and head acceleration. In the example of Figure $1 B$, the two parameters had peaks at 31 and $21 \mathrm{msec}\left(18^{\circ} \mathrm{C}\right)$ after stimulus onset, respectively. On average $(N=6$ fish; $n=18$ trials), peak latencies were $27.5 \pm 1.1 \mathrm{msec}$ for head velocity and $16.3 \pm 0.5 \mathrm{msec}$ for head acceleration. The kinematic profile of the COM was bimodal, with initial velocity and acceleration peaks at 26 and $19 \mathrm{msec}$, respectively, indicating a small displacement of the $\mathrm{COM}$ during C-bend formation, with the second velocity and acceleration peaks at 46 and $33 \mathrm{msec}$ being indicative of the forward propulsion of the body during the return flip (Fig. $1 B$, solid lines). Escape-angle (i.e., the total angular rotation performed by an animal during the C-bend and the return flip), was highly variable and depended on the fish's initial orientation with respect to the underwater loudspeaker. However, no obvious correlation was found between the escape-angle magnitude and the velocity and acceleration peak amplitudes (data not shown).

Exposing goldfish acclimated to $18^{\circ} \mathrm{C}$ to an acute temperature drop of $10^{\circ} \mathrm{C}$ profoundly slows all aspects of the C-start response. Figure 2 compares the kinematic profiles of two C-starts that are from the same animal and have similar escape angles at different temperatures (Fig. 2D). It shows that cooling delayed the start of COM movement (i.e., the onset of the velocity and acceleration changes) by $\sim 20 \mathrm{msec}$ and prolonged the peak time of COM velocity and escape-angle velocity (Fig. $2 A-C)$. Overall $(N=6$; $n=21$ ), the change in temperature resulted in a delay in onset of the velocity curve of $13.8 \pm 1.9 \mathrm{msec}(F=53.18$; $\mathrm{df}=1,19 ; p<$ $0.001)$ and a delay in the onset of the acceleration curve of $13.6 \pm$ $1.9 \mathrm{msec}(F=52.02$; df $=1,19 ; p<0.0001)$. Cooling also decreased C-start motor performance (Fig. 3), as indicated by a 

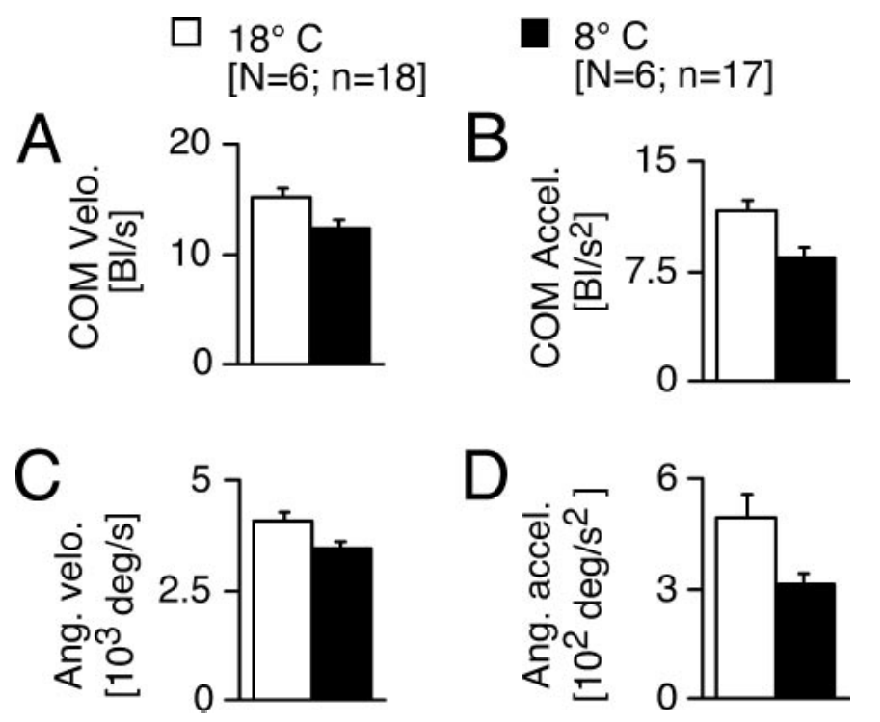

Figure 3. Quantitative effects of cooling on kinematics of C-start escape. Bar plots of bodylength-specific peak velocity $(A)$, body-length-specific peak acceleration $(B)$, peak angular velocity (C), and peak angular acceleration (D) for C-starts evoked at 18 and $8^{\circ} \mathrm{C}$. Cooling significantly decreases motor performance for all measures. Error bars indicate SEM. BI, Body length.

significant reduction of the COM peak velocity $(F=4.67 ; \mathrm{df}=1$, 33 ; $p<0.04)$, COM peak acceleration $(F=8.81 ; \mathrm{df}=1,33 ; p<$ $0.006)$, peak angular velocity $(F=5.17 ; \mathrm{df}=1,29 ; p<0.04)$, and peak angular acceleration $(F=5.48 ; \mathrm{df}=1,23 ; p<0.03)$. However, this decrease in peak performance is primarily attributable to a slowing of the return flip; i.e., the second velocity and acceleration peaks are reduced in cold compared with warm (Fig. $2 A, C)$. In contrast, the first peaks of the velocity and acceleration are similar in magnitude at both temperatures, which suggests that, besides delaying its onset, cooling has little effect on the initial C-bend formation.

Consistent with the prolonged peak in angular velocity in the cold (Fig. $2 \mathrm{~B}$ ), mean escape-trajectory angles increased significantly from $74 \pm 5.9^{\circ}$ at $18^{\circ} \mathrm{C}$ to $97 \pm 6^{\circ}$ at $8^{\circ} \mathrm{C}(F=4.29 ; \mathrm{df}=1$, $68 ; p<0.04)$. Thus, cooling produced an overall shift toward larger escape angles without altering the variability of this parameter (Fig. 4A).

C-bend formation latency, measured as the first detectable movement of the head after stimulus onset, is a behavioral measure directly correlated to the activity in the brainstem escape network that includes the two M-cells (Eaton et al., 1981) and thus yields important information with respect to the temperature dependence of the system. This measure increased significantly on average, from $11.5 \pm 0.3 \mathrm{msec}$ at $18^{\circ} \mathrm{C}$ to $27.3 \pm 0.8$ msec at $8^{\circ} \mathrm{C}(F=202.66 ; \mathrm{df}=1,74 ; p<0.0001)$. In addition, in the cold the distribution of response latencies was much wider than in the warmer temperature, as illustrated by the cumulative distributions in Figure 4B, although the coefficient of variation was relatively constant.

One important measure of C-start motor performance that integrates all of the kinematic parameters described above is the distance traveled by the COM in a specified time interval. Cooling to $8^{\circ} \mathrm{C}$ significantly $(F=12.66 ; \mathrm{df}=1,33 ; p<0.002)$ decreased the distance traveled within $100 \mathrm{msec}$ after stimulus onset compared with warm (Fig. 4C, left). However, after an additional 50 msec the differential was not significant (Fig. $4 C$, middle). Similarly, when the temporal reference was instead response onset there was no significant difference between the distances traveled


Figure 4. Escape trajectory and motor performance during acute temperature exposure. $A$, Cumulative distributions of escape angles at $18(N=9 ; n=34)$ and $8^{\circ} \mathrm{C}(N=9 ; n=36)$, obtained from fish with markers. Note that cooling shifts the distribution to the right (i.e., toward larger escape angles). $B$, Cumulative distributions of response latencies at $18(N=27$; $n=53)$ and $8^{\circ} \mathrm{C}(N=33 ; n=48)$, obtained from unmarked fish in the central region of the arena. Cooling significantly increases the latency of $\mathrm{C}$-start escapes and broadens the latency distribution. C, Bar plots of distance traveled in body lengths within defined time intervals. BI, Body length.

in cold and warm after $100 \mathrm{msec}$ (Fig. 4C, right). This minimization of the differential in performance reflects the fact that warm animals began to decelerate at $\sim 27 \mathrm{msec}$, whereas in colder fish deceleration was delayed by $\sim 24 \mathrm{msec}$ (Fig. $2 C$ ). Nevertheless, the observed difference within the initial $100 \mathrm{msec}$ after stimulus onset might be of biological relevance because this is a common strike time of piscivores attacking prey (Webb, 1978b).

A vital property of the $\mathrm{C}$-start is its directionality (i.e., the ability of the fish to turn away from the auditory stimulus source), at least in open-field conditions (Eaton and Emberley, 1991).Thus, we analyzed the effects of cooling on response directionality for fish that were in the middle of the tank and had a clear directional choice (i.e., with only one body side facing the underwater loudspeaker). In the majority of trials the initial C-bend was directed away from the loudspeaker and turns toward the stimulus were rare. However, as shown in Figure 5, the percentage of turns toward the stimulus increased significantly $\left(p<0.01 ; \chi^{2}\right.$ test $)$ in the cold, from $14 \%$ at $18^{\circ} \mathrm{C}(N=24 ; n=66)$ to $36 \%$ at $8^{\circ} \mathrm{C}(N=27 ; n=62)$. In addition, temperature also affected other aspects of the C-start escape trajectory. As noted, one camera recorded the escape behavior of three animals in the tank, which in many trials included sequences with at least one fish close to the wall. We treated fish located within a distance of two-thirds of a body length from the wall as having an obstructed path away from the stimulus (Fig. 5). In such an instance a star- 


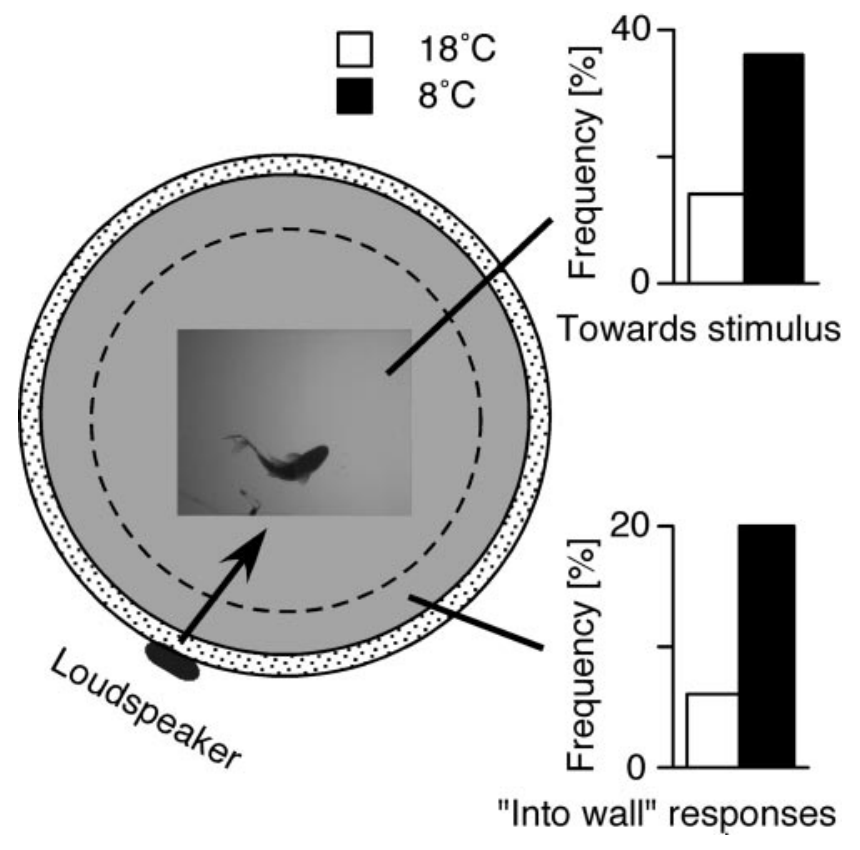

Figure 5. Effects of temperature on response direction. Left, Top view of the tank, illustrating the location and relative size of the high-magnification region. The inappropriate response direction for fish within the zone defined by the dashed circle is defined as toward the stimulus, and the corresponding response frequencies in 8 and $18^{\circ} \mathrm{C}$ are plotted at the upper right. In contrast, when the fish is at least partially in the outer zone, the inappropriate response is now defined as one during which it turns into the wall. The response frequencies for this case are plotted at the lower right.

tled goldfish at $18^{\circ} \mathrm{C}$ typically performed a C-bend away from the wall, even if that meant turning toward the auditory stimulus, and "inappropriate" turns into the wall were observed in only 2 of 32 cases $(6 \%)$. However, at $8^{\circ} \mathrm{C}$ this ratio increased to 18 of 92 cases (20\%) (Fig. 5).

The apparent role of the M-cells in triggering C-starts makes behavioral responsiveness, specifically the probability of eliciting a C-start, another important indicator of the activity in the escape network during acute temperature exposure. Responsiveness was tested by using a randomized order of stimulus intensities presented at random time intervals (see Materials and Methods). The same presentation pattern was used for all the experiments, and there was no sign of habituation or sensitization with this paradigm. Individual C-starts of all three animals in a given trial were counted and transformed into a trial probability (i.e., 0, $0.33,0.67$, or 1$)$, and each group of fish was tested in warm and cold. Under these conditions, cooling significantly increased the mean relative frequency for sound-evoked C-starts by $\sim 33 \%$ compared with warm $(31.5 \pm 2.4$ vs $23.5 \pm 2.2 \% ; F=4.76 ; \mathrm{df}=$ $1,275 ; p<0.03)$. The left graph in Figure $6 \mathrm{~A}$ demonstrates this finding for pooled data over the entire range of auditory stimuli used, whereas the right illustrates that the increase in escape probability in the cold was found for distinct intensities. At both temperatures, response probability and stimulus intensity showed a roughly logarithmic relationship (Fig. 6A, right), but because of the inherent variability of the stimulus amplitude at different areas of the experimental tank and the limited intensity range of the underwater loudspeaker, absolute response threshold or saturation intensity could not be established.

We considered the possibility that the three fish might not respond independently in one or both temperature conditions by performing simple binomial analyses of the response distribu-

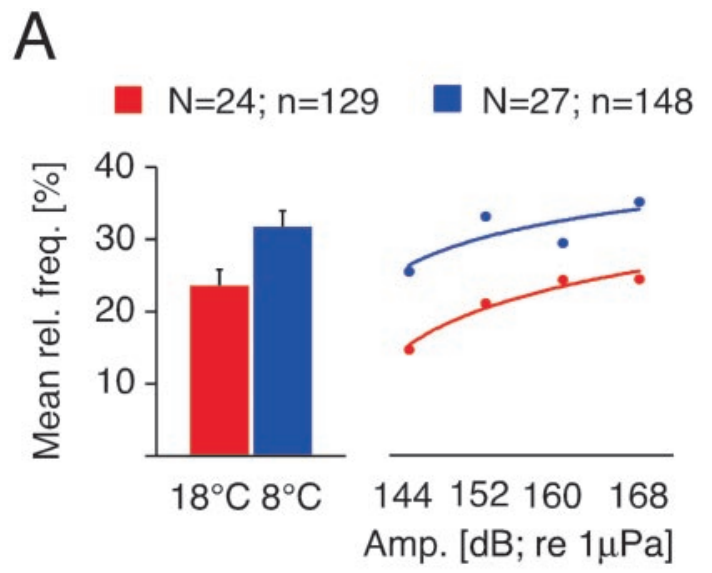

B

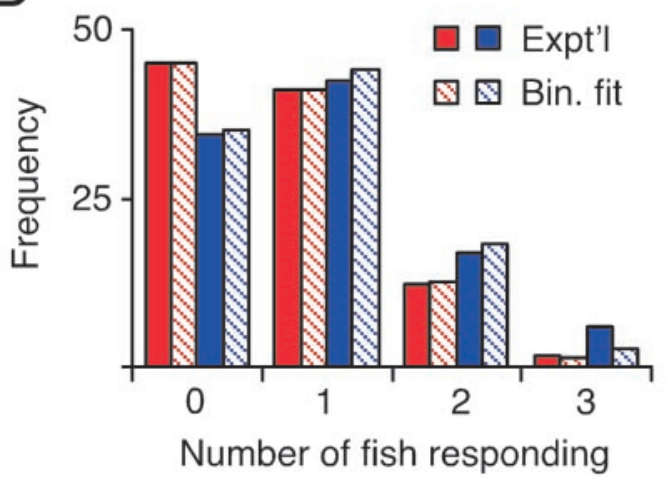

Figure 6. A, Relationship between escape responsiveness and acute temperature exposure. Left, Bar plots of mean relative frequencies of sound-evoked C-starts calculated from individual experimental trials with three animals each at 18 (red) and $8^{\circ} \mathrm{C}$ (blue). For the right part of the graph the same data were separated into four distinct intensity bins ranging from 140 to148, 149 to 156,157 to 164,165 to $170 \mathrm{~dB}$, respectively. $B$, Bar plots of the frequencies (\%) with which $0,1,2$, or 3 fish responded per trial (solid) at the two experimental temperatures, compared with the predicted distributions (hatched), assuming a simple binomial model (see Results for details and statistics).

tions (frequencies of $0,1,2$, and 3 escapes per trial) in the cold and warm. Specifically, the data were fit with the expression:

$$
p_{x}=\frac{3 !}{(3-x) ! x !} p^{x}(1-p)^{3-x}
$$

where $p_{x}$ is the probability of $x$ escapes in a trial, $p$ is the average probability of escapes per fish, and $n=3$ fish. As shown in Figure $6 B$, both experimental distributions conformed to the binomial predictions ( $p>0.05 ; \chi^{2}$ test), with the derived escape probabilities equivalent to those found for the two populations ( $p$ warm $=0.235 ; p$ cold $=0.295$ ). Thus, in each temperature condition the three fish responded independently and with the same average probability, which are basic properties of a simple binomial.

\section{Effects of cooling on the M-cell synaptic responses and membrane properties}

The sound-evoked C-starts are presumably triggered by the activation of auditory afferents that have mixed electrical and chemical excitatory synapses on the distal lateral dendrite of the M-cell (Furshpan, 1964; Lin and Faber, 1988a,b). To correlate the observed effects of cooling on the escape behavior with physiological changes in this network, intracellular responses to sound 
clicks and antidromic stimulation were recorded sequentially from the M-cell soma and lateral dendrite (Fig. 7A). Because responses to posterior eighth-nerve stimulation are generated in the dendrite, their amplitudes are maximal distally and smaller in the soma, and the same relationship holds for sound-evoked PSPs (Fig. 7B, dashed vs solid lines) (see also Casagrand et al., 1999). The opposite is the case for the antidromic action potential, which is generated at the initial segment of the axon-hillock region of the $\mathrm{M}$-axon and propagates passively (Furshpan and Furukawa, 1962) into the soma and dendrite (Fig. 7C). Thus, the passive spread of these potentials along the dendrite is an indicator of its cable properties.

At $18^{\circ} \mathrm{C}$ the sound-evoked PSPs have multiple peaks, which are most clearly delineated with distal dendrite recordings and typically are at a frequency twice that of the stimulus (Figs. $7 B$, $8 B$ ). The fast peaks are spike-like and thus are comparable with those of the electrotonic component of EPSPs evoked by direct stimulation of the posterior eighth nerve (Lin and Faber, 1988a). This is consistent with the notion that these peaks are mediated by electrical synapses, whereas the underlying depolarizing envelope is chemically mediated. Acute cooling of the fish brain from 18 to $8^{\circ} \mathrm{C}$ produced distinct, but reversible changes in the latency, waveform, and amplitude of the sound-evoked PSPs. In the example of Figure $7 B$, the intradendritic PSP latency increased by $1.3 \mathrm{msec}$ at $8^{\circ} \mathrm{C}$, whereas on average it increased by $1.5 \pm 0.2 \mathrm{msec}$ from $1.3 \pm 0.07$ in the warm to $2.7 \pm 0.2 \mathrm{msec}$ in the cold $(N=6)$. In contrast, the conduction time of the antidromic action potential of the M-axon increased by only $0.3 \pm 0.02 \mathrm{msec}(N=6)$. Although the eighth-nerve conduction velocity is slower than that of the M-axon, the conduction distance is at least an order of magnitude shorter, which suggests that the increased delay of the PSP was mainly synaptic in origin. Cooling to $8^{\circ} \mathrm{C}$ produced a substantial broadening of the antidromic spike, which appears to be mostly attributed to a delayed and slowed spike repolarization (Fig. 7C, left). Similarly, cooling also simplified the waveform of the intradendritic PSP by reducing the number of peaks of a typically multipeak response at $18^{\circ} \mathrm{C}$ (Figs. $7 \mathrm{~B}$, left dashed lines; $8 B, C)$

Despite the behavioral observation of a rise in escape probability with cooling, the peak PSP amplitudes in the dendrite at 8 and $18^{\circ} \mathrm{C}$ were comparable (Fig. $7 \mathrm{~B}$ ). Overall, when average values were compared for four experiments with sequential recordings from the two sites, there was a small but insignificant increase $(11 \%)$ in the dendritic peak PSP amplitude in the cold, and a larger but significant increase in the somatic peak amplitude (24\%; $p<0.05$; paired $t$ test). Thus, given the relatively greater effect at the soma as opposed to the locus of synaptic input, we asked whether changes in dendritic cable properties might contribute to the increased behavioral responsiveness. Sequential measurements from multiple sites of PSP and antidromic spike amplitudes $(N=3)$ showed that, indeed, cooling changed the cable properties in the lateral dendrite, as indicated by a reduced fractional decay of the PSP from dendrite to soma and less spatial attenuation of the intradendritic spike when comparing responses obtained in the cold and warm. Specifically, there was a significant increase of the mean length constant $\lambda$, from $275 \pm 43$ to $577 \pm 20 \mu \mathrm{m}$ ( $p<0.02$; $t$ test $)$ in the orthodromic direction, and from $226 \pm 38$ to $346 \pm 25 \mu \mathrm{m}$ in the antidromic direction ( $p<0.03 ; t$ test) (Fig. 7B,C). Thus, although the sound-evoked PSP could be smaller at the cold than at the warmer temperature when recorded at the dendritic locus of synaptic input, it could nevertheless be larger in the soma (Fig. $7 B$ ). An additional mechanism for the increased behavioral responsiveness could be a de-
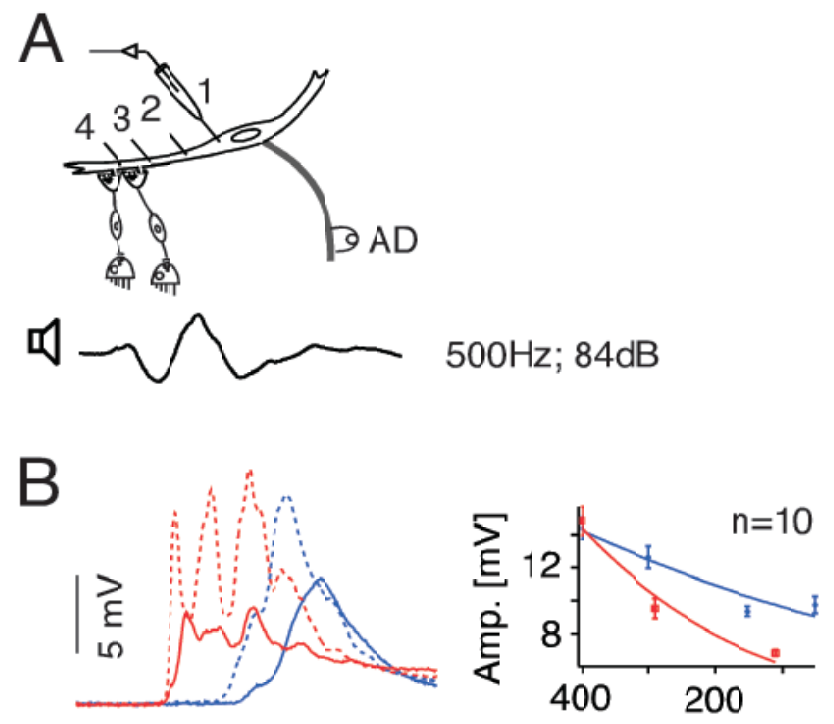

$2 \mathrm{~ms}$

Distance from $\mathrm{AC}[\mu \mathrm{m}]$

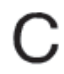

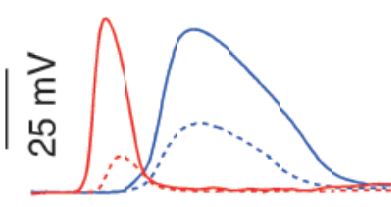

$1 \mathrm{~ms}$

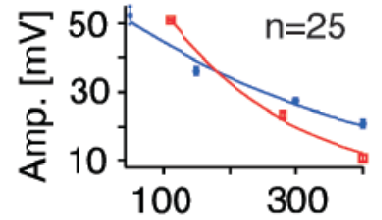

Distance from AC $[\mu \mathrm{m}]$
Figure 7. Temperature dependence of sound-evoked PSPs and passive membrane properties of the M-cell. $A$, Schematic showing that M-cell potentials evoked by antidromic and sound stimulation were recorded successively at up to four different sites along the M-cell soma (1) and lateral dendrite (2-4) at two different temperatures. B, Somatic (solid lines, site 1 ) and distal dendritic (dashed lines, site 4) sound-evoked PSPs (left) and plot of their decrement along the dendrite (right) at 18 (red) and $8^{\circ} \mathrm{C}$ (blue). The recorded sound stimulus (above) has the same time scale as PSPs. C, Somatic (solid lines) and distal dendritic (dashed lines) antidromic action potentials (left) and their decrement along the dendrite (right) at 18 (red) and $8^{\circ} \mathrm{C}$ (blue). Note that the decrement in amplitude between the two recordings sites is reduced at $8^{\circ} \mathrm{C}$, for both responses, which is reflected in a distinct increase of the space constant. All traces in $B$ and Care averages of 10 sweeps. Plots indicate means \pm SEM ( $n=$ number of traces). AC, Center of the axon cap, which surrounds the axon hillock and initial segment; AD, antidromic.

polarization of the M-cell membrane induced by cooling. However, within the temperature range tested the membrane potential remained constant, being on average $77 \pm 0.7 \mathrm{mV}$ at $8^{\circ} \mathrm{C}$ and $78.5 \pm 1.1 \mathrm{mV}$ at $18^{\circ} \mathrm{C}(N=17)$.

The experiments described above required mapping response amplitudes sequentially along the soma-dendrite membrane, changing the temperature while maintaining intracellular recording and then repeating the mapping procedure in reverse order. To control for the possibility that the repeated penetrations of the cell compromised the integrity of the amplitude measurements we performed another series of experiments $(N=2)$ in which the intracellular responses were recorded simultaneously at the distal dendrite and soma and the temperature was increased after collecting data at $8^{\circ} \mathrm{C}$ (Fig. $8 \mathrm{~A}$ ). Representative recordings, shown in Figure $8, B$ and $C$, confirm that cooling decreased the relative decay of the PSP, by $33 \%$, and the antidromic spike, by $15 \%$, compared with warm. In the same experiments, hyperpolarizing and depolarizing current pulses were in- 
A

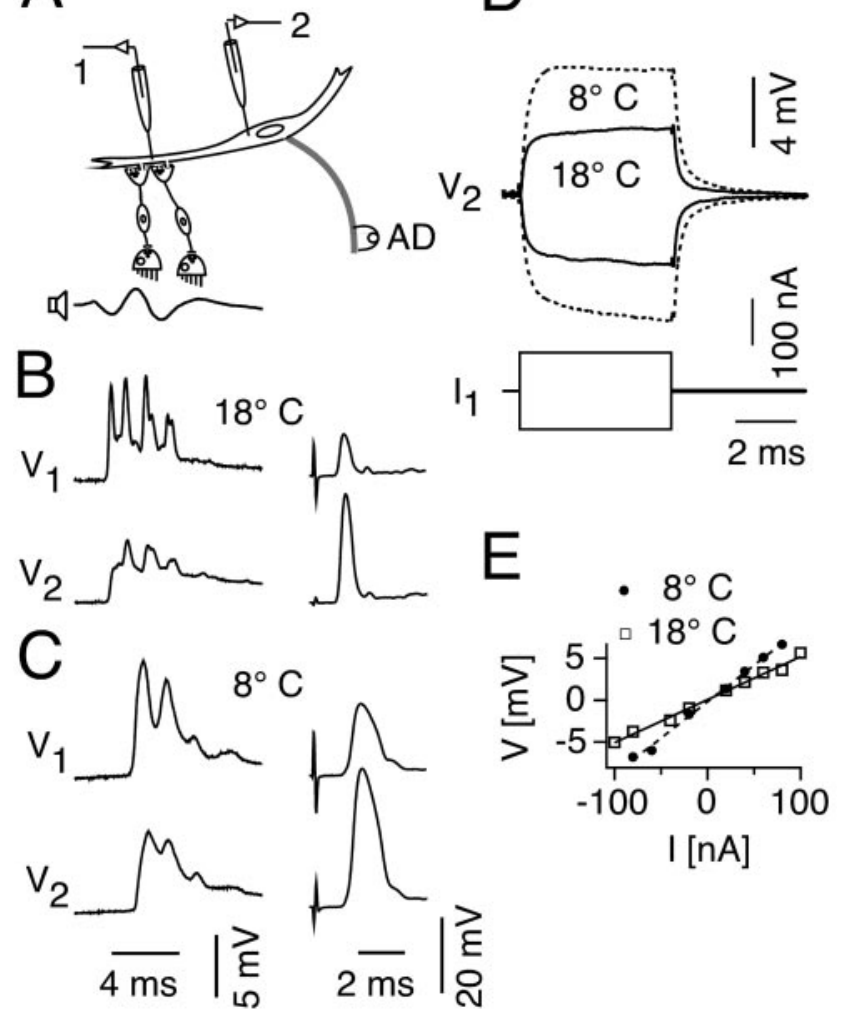

Figure 8. Temperature dependence of M-cell responses and transfer resistance. $A$, The $M$-cell was penetrated with two microelectrodes at a distal dendritic site and the soma for simultaneous potential recording and current injection at two different temperatures. $B$, Dendritic (upper left) and somatic (lower left) recording of a sound-evoked PSP ( $300 \mathrm{~Hz}, 84 \mathrm{~dB}$ ) and corresponding antidromic spike (upper right and lower right, respectively) at $18^{\circ} \mathrm{C}$. C, Same recordings as in $B$, but at $8^{\circ} C$. D, Changes in somatic membrane potential produced by an $80 \mathrm{nA}$ dendritic current pulse in the hyperpolarizing and depolarizing directions at 18 (solid line) and $8^{\circ} \mathrm{C}$ (dashed line). Traces in $B-D$ are averages of 10 sweeps. $E$, Plot of the corresponding voltage-current relationship $\left(V_{2}\right.$ vs $\left.I_{1}\right)$ at 18 (solid line) and $8^{\circ} \mathrm{C}$ (dashed line).

jected through the intradendritic electrode, and the resulting change in membrane potential was recorded in the soma to analyze the effects of temperature on transfer resistance, defined as $R_{t}=V_{\text {soma }} / I_{\text {dend }}($ Fig. $8 D$ ). By comparing this measure in the two temperatures, we can obtain a direct indication of the change in effectiveness at the soma of the same (synaptic) current at its source, the dendrite. Comparing the slopes of the resulting V/I plots at the two temperatures shows a clear increase in $R_{t}$ from 53 $\mathrm{k} \Omega$ at $18^{\circ} \mathrm{C}$ to $85 \mathrm{k} \Omega$ at $8^{\circ} \mathrm{C}$ (Fig. $8 E$ ). The $\sim 60 \%$ increase in $R_{t}$ is consistent with the $50-100 \%$ increase in $\lambda$.

Taken together, the physiological results are consistent with the notion that cooling increases the input resistance $\left(R_{\text {in }}\right)$ in the $\mathrm{M}$-cell, and thus the same synaptic conductance change should produce larger responses in the cold than in the warm. A good example of this effect is the antidromic action potential, which is generated at the axon hillock and is often larger in the cold at both recording sites compared with $18^{\circ} \mathrm{C}$ (Fig. $8 \mathrm{~B}, \mathrm{C}$ ). Theoretically, the same sound-evoked dendritic PSP should be more effective at the soma in the cold than in the warm in bringing the M-cell to threshold, and this change in cable properties might also compensate for any reduction in the synaptic coupling potential and excitatory conductance change.

To test this hypothesis functionally we measured the input resistance, $R_{\mathrm{in}}$, and M-cell excitability in the warm and cold ( $n=$

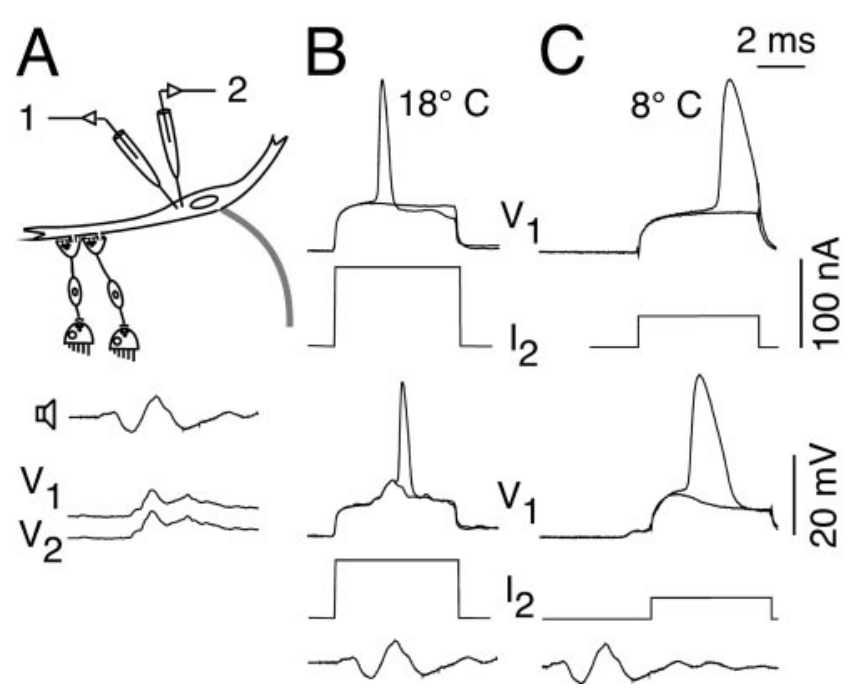

Figure 9. Temperature dependence of the M-cell input resistance $\left(R_{\text {in }}\right)$. $A$, The cell was penetrated with two intrasomatic electrodes for simultaneous potential recording and current injection at two different temperatures (top). The resemblance of the two sound-evoked PSPS indicates a close proximity of the electrodes (bottom, $18^{\circ} \mathrm{C}$ ). B, M-cell action potential evoked, at threshold either by a $91 \mathrm{nA}$ depolarizing current pulse alone (top) or by a $66 \mathrm{nA}$ current pulse paired with a sound-evoked PSP (bottom) at $18^{\circ} \mathrm{C}$. C, Same threshold conditions at $8^{\circ} \mathrm{C}$ as in $B$, but with either a $41 \mathrm{nA}$ depolarizing current pulse alone (top) or by a $28 \mathrm{nA}$ current pulse paired with a sound-evoked PSP (bottom). The recorded sound stimuli ( $300 \mathrm{~Hz}, 75 \mathrm{~dB}$ ) have the same time scale as recordings. Note that cooling increases $R_{\text {in }}$ and lowers the threshold current.

2) using two intrasomatic electrodes, for simultaneous voltage recording and current injection (Fig. $9 A$ ). Cooling to $8^{\circ} \mathrm{C}$ increased $R_{\text {in }}$ by $\sim 120 \%$ and decreased the threshold current by more than half compared with $18^{\circ} \mathrm{C}$ (Fig. $9 B, C$, top). Similarly, when a sound-evoked PSP was paired with a current pulse, the added current needed to bring the $\mathrm{M}$-cell to threshold dropped by more then half with cooling (Fig. 9B, $C$, bottom). This indirect method of measuring threshold at different temperatures was necessary because even with the maximum sound intensities (104 $\mathrm{dB})$ the evoked PSP was not sufficient to bring the M-cell to threshold at either temperature in the electrophysiological studies. This might be attributable to an effect of electrode penetration that likely decreases input resistance and thus increases the threshold current in the M-cell, as well as to the use of an anesthetized preparation. In addition, sound stimuli in air provide only the pressure component of an auditory stimulus and lack the particle acceleration component present when using underwater stimulation (Popper and Fay, 1993, Casagrand et al., 1999), which could explain why even less-intense auditory stimuli were sufficient to elicit a C-start in the behavioral experiments.

In addition to their monosynaptic excitation of the M-cell, auditory afferents also activate a feedforward inhibitory network that regulates the excitability of the neuron (Faber and Korn, 1978, Faber et al., 1991, Oda et al., 1998). A distinct sensitivity of cerebellar inhibitory circuits to cooling has been shown previously in goldfish (Friedlander et al., 1976), and experiments ( $n=$ 3 ) were performed to determine whether changes in temperature also affect the M-cell inhibitory system and, thus, escape responsiveness. In the M-cell, inhibitory responses are not associated with frank potential changes, because unless the cell is experimentally loaded with $\mathrm{Cl}^{-}$, the IPSP equilibrium potential is close to the resting potential (Faber and Korn, 1978). Thus, the inhibitory synaptic conductance $\left(G_{\text {IPSP }}\right)$ can be calculated from measurements of the reduction (shunt) in the amplitude of a passively conducted test antidromic action potential after the 


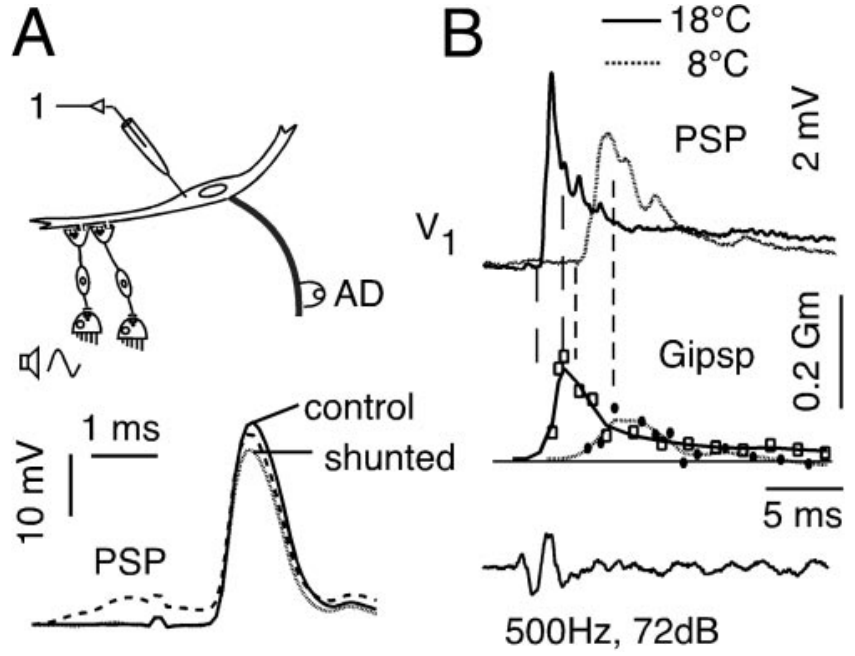

Figure 10. Temperature dependence of feedforward inhibition in the escape network. $A$, M-cell potentials were evoked by pairing a sound-evoked PSP with the antidromic action potential. Superimposed records of the antidromic action potential when evoked alone (control) and when paired with a preceding sound evoked PSP (dashed line). To better illustrate the magnitude of the action potential shunt, the PSP alone (data not shown) was digitally subtracted from the composite response (shunted). Note that because there is only a small inhibitory driving force, the PSP itself is predominantly excitatory (see Results). $B$, The magnitude of this shunt was used to calculate the inhibitory conductance, $G_{\text {IPSP. }}$. Top, Sound-evoked PSPs; middle, the calculated corresponding inhibitory conductances $\left(G_{\text {IPSP }}\right)$ obtained by varying interstimulus interval and expressed as fractions of input conductance $\left(G_{m}\right)$. Solid traces are at $18^{\circ} \mathrm{C}$ and dotted traces, $8^{\circ} \mathrm{C}$. The first vertical dashed line of each pair indicates the time of PSP onset and the second corresponds to the peak of $G_{\text {IPSP. }}$. Note the decrease in amplitude of the inhibition and the increase in its time to peak at $8^{\circ} \mathrm{C}$. All traces in $A$ and $B$ are the averages of five sweeps.

activation of the feedforward inhibitory network (Fig. 10A). That is, $G_{\text {IPSP }}=r /(1-r) G_{\mathrm{m}}$, where $r$ is the fractional reduction in spike height and $G_{\mathrm{m}}$ is the M-cell input conductance (Faber and Korn, 1982), which may change with the experimental condition. In our experiments we recorded the time course of $G_{\text {IPSP }}$ at 8 and $18^{\circ} \mathrm{C}$ by stimulating the feedforward inhibitory network with a sound stimulus (PSP) (Fig. 10A,B) followed by an antidromic test stimulus at progressively longer time intervals ranging from 0.5 to $30 \mathrm{msec}$. The result of a representative experiment, shown in Figure $10 B$, indicates that cooling markedly decreased the magnitude and onset of $G_{\text {IPSP }}$ compared with warming (Fig. $10 B$, middle). In addition, the rise time of $G_{\text {IPSP }}$ increased in the cold, with the consequence that the time window between the onset of a sound-evoked PSP and the time of the peak inhibition is approximately twice as long in cold as in warm (Fig. $10 \mathrm{~B}$ ). It should be noted that the magnitude of $G_{\text {IPSP }}$ is expressed as a fraction of the input conductance (Faber and Korn, 1982), which is also decreased by cooling. Thus, the reduction in the inhibitory conductance is actually greater than suggested in Figure $10 \mathrm{~B}$.

\section{Discussion}

Temperature-induced changes of neuron properties and behavioral responsiveness

The effects of acute temperature changes on the escape behavior of goldfish and on the basic biophysical properties of the M-cell and its synaptic inputs can provide insights about the mechanisms that may underlie the proper expression of this behavior. Multiple mechanisms combine to increase $\mathrm{M}$-cell responsiveness to sound at lower temperatures. First, the input resistance of the $\mathrm{M}$-cell increased, so that weaker synaptic conductance changes yielded dendritic responses comparable with those at the warmer temperature. Second, the cable properties in the lateral dendrite were altered by cooling, as indicated by a longer space constant and a reduced centripetal attenuation of a given dendritic input. Third, cooling decreased the magnitude and delayed the onset of feedforward inhibition of the M-cell. These cellular mechanisms combine to explain the behavioral observation that C-starts are more easily elicited in fish at colder temperatures, and they might serve to compensate for the reduced or more sluggish execution of a vital response. Behavioral hyperexcitability caused by acute cooling has been shown previously in goldfish together with indications of a distinct temperature sensitivity of cerebellar inhibitory interneurons (Friedlander et al., 1976). Acute cooling also increases the escape jetting performance and the firing rate in the squid giant and nongiant fiber pathways, and a temperaturedependent reduction of central inhibition has been suggested as the likely mechanism (Neumeister et al., 2000). In addition, the effects of temperature on membrane properties, synaptic gain, and conduction delays, and their possible implications for behavioral performance, are well documented (Prosser and Nelson, 1981; Montgomery and MacDonald, 1990). In the M-cell system, factors contributing to an increased behavioral responsiveness may be correlated with acute behavioral compensation for the negative effects on motor performance and directionality. For example, the observed lowering of the escape threshold could effectively increase the distance at which flight from an attacking predator is triggered in nature. Indeed, such an inverse relationship between flight distance and temperature has been described for lizards (Rand, 1964). In this context, it is interesting to note that acute warming or heat shock has been shown to increase the vulnerability of fish to predator attack (Webb and Zhang, 1994; Yocom and Edsall, 1974), suggesting that warming increases the threshold in the M-cell system and decreases escape responsiveness. This would confirm the specific sensitivity of the M-cell system to acute temperature shifts and underlines the significance of temperature for nervous system function and behavior (Montgomery and MacDonald, 1990).

The temperature-dependent changes in M-cell input resistance and dendritic space constant are most likely caused by a reduction in resting $\mathrm{K}^{+}$conductance. The M-cell membrane potential, which did not change with temperature, was typically at approximately $-78 \mathrm{mV}$, suggesting that the membrane is close to the $\mathrm{K}^{+}$equilibrium potential (Faber and Korn, 1978), and $\mathrm{Na}^{+}$ and $\mathrm{Cl}^{-}$conductances are quite low at rest. In confirmation, neither $\mathrm{Cl}^{-}$loading nor pharmacologically blocking inhibition have detectable effects on M-cell membrane potential or input conductance (Faber and Korn, 1988). Moreover, the distinct broadening of the antidromic action potential at $8^{\circ} \mathrm{C}$ (Figs. 7-9) is consistent with a greater temperature sensitivity of currents underlying spike repolarization: namely, a delayed onset and decreased magnitude of voltage-dependent potassium conductance and/or slower inactivation kinetics of sodium channels (Frankenhaeuser and Moore, 1963, Klee et al., 1974). A similar spike broadening in the eighth-nerve afferents, combined with the increased $\mathrm{M}$-cell time constant caused by the doubling of the input resistance, would account for the slower onset and prolonged duration of the sound-evoked coupling potential in the cold. Comparable thermal dependencies of excitable cells have been described for invertebrates (Hodgkin and Katz, 1949; Winter, 1973) and vertebrates (Volgushev et al., 2000). In some other systems cooling also led to a depolarization of the cell membrane, which we did not observe. In this context our results are comparable with the temperature sensitivity of squid giant axon, which exhibits a similar increase of spike duration with cooling, but no 
Table 1. Components of C-start latencies at 18 and $8^{\circ} \mathrm{C}$

\begin{tabular}{|c|c|c|c|c|c|}
\hline & Sensory processing time ${ }^{a}$ & $\mathrm{M} \cdot$ cell processing time $^{b}$ & Conduction time & Muscle activation & C-start latency ${ }^{c}$ \\
\hline $18^{\circ} \mathrm{C}$ & $1.3 \pm 0.07(n=6)$ & $1-1.5$ & $1.7 \pm 0.09^{d}\left(17-22^{\circ} \mathrm{C}\right)$ & $7.5^{e}$ & $11.5 \pm 0.3(n=53)$ \\
\hline $8^{\circ} \mathrm{C}$ & $2.7 \pm 0.2(n=6)$ & $2-2.5$ & $2.0^{f}$ & $20^{g}$ & $27.3 \pm 0.8(n=48)$ \\
\hline
\end{tabular}

All values are in means \pm SEM.

${ }^{a}$ Time from onset of sound stimulus measured at the position of the fish to dendritic PSP.

${ }^{b}$ Estimated value based on the time window between onsets of dendritic PSP to IPSP peak (Fig. $10 \mathrm{~B}$ ).

Time from stimulus onset to C-start formation.

${ }^{d}$ Time from M-cell spike to EMG onset (Zottoli, 1977).

${ }^{e}$ Time from EMG onset to C-start formation (Foreman and Eaton, 1993).

'This value was determined by adding the temperature-dependent increase in conduction time $(0.3 \pm 0.02 \mathrm{msec} ; n=6)$ to the published ${ }^{d}$ value.

${ }^{9}$ This value was determined by subtracting the sensory processing time, the $\mathrm{M}$-cell processing time, and the conduction time from the C-start formation latency.

Modified from Zottoli et al. (1995).

change in membrane potential between 5 and $20^{\circ} \mathrm{C}$ (Hodgkin and Katz, 1949).

\section{Temperature-induced effects on escape directionality}

In addition to the increased behavioral responsiveness, other aspects of the C-start also showed distinct temperature sensitivities that may be correlated with electrophysiological changes in the M-cells and their associated networks. There was a significant increase in apparent directional errors in the cold environment, namely an increase in responses toward the stimulus instead of away from it and a distinct increase in inappropriate responses into the tank wall. In other words, cooling affects the directional decision-making process underlying the escape. Although the neurobiological mechanism by which the M-cell system solves the directional discrimination task for an underwater auditory stimulus is not yet fully understood (Popper and Fay, 1993; Eaton et al., 1995, Casagrand et al., 1999), it seems clear that the initial turn away from the stimulus is decided by a single action potential in either the left or right M-cell (Zottoli, 1977; Eaton et al., 1991). Because of its role as an all-or-none initiator of the response, the M-cell should have a high firing threshold to avoid frequent and inappropriate responses. The requirement for an instantaneous yet directional response, on the other hand, would imply that a given stimulus brings both M-cells close to threshold and that only a small bias of sensory-evoked excitation and/or inhibition in the system determines which of the two M-cells reaches threshold. Indeed, the firing threshold of the M-cell is relatively high (15-20 $\mathrm{mV}$ above the resting potential), and interactions between auditory-evoked excitatory and inhibitory inputs (Faber and Korn, 1978; Zottoli and Faber, 1980; Oda et al., 1998) determine whether an M-cell reaches that point. Furthermore, it has been suggested that an imbalance in the feedforward inhibition to the two M-cells plays a role in determining escape direction (Faber et al., 1991; Eaton et al., 1995; Hatta and Korn, 1999). Our physiological results showed that cooling lowered the behavioral threshold for spike initiation in the M-cell, presumably because of the effects of an increased membrane resistance; at the same time cooling delayed the onset and magnitude of feedforward inhibition. Thus, the temporal window was broadened during which the decision to respond is reached and the escape direction is selected. These changes in the balance between the relative magnitude and timing of excitation and inhibition in the system with cooling shifted the directionality of the response to almost the level of chance, by bringing both M-cells closer to threshold and at the same time reducing the proposed discriminatory role of inhibition.

\section{Temperature effects on motor performance}

All of the kinematic parameters measured in this study show significant slowing of C-start motor performance at $8^{\circ} \mathrm{C}$ com- pared with those recorded at $18^{\circ} \mathrm{C}$ (Figs. 2-4). Similar effects of acute cooling on escape motor performance have been described for goldfish and other fish species (Webb, 1978b; Temple and Johnston, 1997; Johnson et al., 1998). The slowing is primarily attributable to an increase in the duration of the propulsion stage, with corresponding reduced peak $\mathrm{COM}$ velocity and acceleration values. The prolonged propulsion stage led to over-rotation and thus had a direct influence on the escape trajectory and turning angle. However, the initial C-start formation appears less affected by acute cooling and shows similar velocity and acceleration values at both temperatures. Although the C-start formation is closely correlated to the all-or-none activity of one of the M-cells (Nissanov and Eaton, 1989), the more flexible and graded propulsion stage is thought to involve other reticulospinal neurons (Nissanov et al., 1990). Thus, the similarities in the kinematics of C-start formation would be consistent with the idea that the M-cells triggered the responses studied at both temperatures. This notion is also supported by the fact that the probability of eliciting a C-start was significantly increased in the cold (Fig. 6), because ablation of the M-cells has been shown to decrease escape probability (Zottoli et al., 1999). In addition, the C-start latency at $18^{\circ} \mathrm{C}$ was comparable with that reported previously (Eaton et al., 1977).

C-start latency, measured as the time from stimulus onset to C-start formation, increased, on average, by $15.8 \mathrm{msec}$ with cooling (Fig. 4). The physiological results showed that this increment was distributed throughout the different stages of the escape network; however, most of the increase appears to be related to muscle activation. Table 1 dissects the $\mathrm{C}$-start latency into its successive components, namely presensory processing time from sound to PSP onset, M-cell processing time, $\mathrm{M}$-axon conduction time, time to muscle EMG activity, and muscle contraction time. Our electrophysiological data on the first three components indicate that the major source of the increased latency in the cold is caused by slowing of muscle activation by $\sim 13 \mathrm{msec}$. However, equally important is that the sensory and M-cell processing time are each increased by $\sim 100 \%$. This increase in the time allowed to reach a decision to respond and select its direction is one consequence of coordinated changes in the network and intrinsic M-cell properties that combine to support behavioral hyperexcitability in the cold. More generally, our results suggest that both the relative magnitudes of excitation and inhibition and their timing may determine the expression of a behavior and its modification.

\section{References}

Bennett AF (1985) Temperature and muscle. J Exp Biol 115:333-344.

Bennett AF (1990) Thermal dependence of locomotor behavior. Am J Physiol 40:447-469. 
Blaxter JHS, Fuiman LA (1990) The role of sensory systems of herring larvae in evading predatory fishes. J Mar Biol Ass UK 61:851-869.

Casagrand JL, Guzik AL, Eaton RC (1999) Mauthner and reticulospinal response to the onset of acoustic pressure and acceleration stimuli. J Neurophysiol 82:1422-1437.

Domenici P, Blake RW (1997) The kinematics and performance of fast-start swimming. J Exp Biol 200:1165-1178.

Eaton RC (1991) The neuroethology of the Mauthner system. Brain Behav Evol 37:245-332.

Eaton RC, Emberley DS (1991) How stimulus direction determines the trajectory of the Mauthner-initiated escape response in a teleost fish. J Exp Biol 161:469-487.

Eaton RC, Hackett JT (1984) The role of the Mauthner cell in fast-starts involving escapes in teleost fishes. In: Neural mechanisms of startle behavior. (Eaton RC, ed), pp 213-266. New York: Plenum.

Eaton RC, Bomardieri RA, Meyer OH (1977) The Mauthner-initiated startle response in teleost fish. J Exp Biol 66:65-81.

Eaton RC, Lavender WA, Wieland CM (1981) Identification of Mauthnerinitiated patterns in goldfish: evidence from simultaneous cinematography and electrophysiology. J Comp Physiol [A] 144:521-531.

Eaton RC, DiDomenico R, Nissanov J (1991) The role of the Mauthner cell in sensorimotor integration by the brainstem escape network. Brain Behav Evol 37:271-285.

Eaton RC, Canfield JG, Guzik AL (1995) Left-right discrimination of sound onset by the Mauthner system. Brain Behav Evol 46:165-179.

Eaton RC, Lee RKK, Foreman MB (2001) The Mauthner cell and other identified neurons of the brainstem escape network of fish. Prog Neurobiol 63:467-485.

Faber DS, Korn H (1978) Electrophysiology of the Mauthner cell: basic properties, synaptic mechanisms, and associated networks. In: Neurobiology of the Mauthner cell (Faber DS, Korn H, eds), pp 47-131. New York: Raven.

Faber DS, Korn H (1982) Transmission at a central inhibitory synapse. I. Magnitude of the unitary postsynaptic conductance change and kinetics of channel activation. J Neurophysiol 48:654-678.

Faber DS, Korn H (1988) Unitary conductance changes at teleost Mauthner cell glycinergic synapses: a voltage-clamp and pharmacologic analysis. J Neurophysiol 60:1982-1999.

Faber DS, Fetcho JR, Korn H (1989) Neuronal networks underlying the escape response in goldfish: general implications for motor control. Ann NY Acad Sci 563:11-33.

Faber DS, Korn H, Lin J-W (1991) The role of medullary networks and postsynaptic membrane properties in regulating Mauthner cell responsiveness to sensory excitation. Brain Behav Evol 37:286-297.

Fay RR, Ream TJ (1992) The effects of temperature change and transient hypoxia on auditory nerve fiber response in the goldfish (Carassius auratus). Hearing Res 589:9-18.

Fetcho JR (1991) The spinal network of the Mauthner cell. Brain Behav Evol 37:298-315.

Foreman MB, Eaton RC (1993) The direction change concept for reticulospinal control of goldfish escape. J Neurosci 13:4101-4113.

Frankenhaeuser B, Moore LE (1963) The effects of temperature on sodium and potassium permeability changes in myelinated nerve fibers of Xenopus laevis. J Physiol (Lond) 169:431-437.

Friedlander MJ, Kotchabhakdi N, Prosser CL (1976) Effects of cold and heat on behavior and cerebellar function in goldfish. J Comp Physiol [A] 112:19-45.

Furshpan EJ (1964) Electrical transmission at an excitatory synapse in a vertebrate brain. Science 144:878-880.

Furshpan EJ, Furukawa T (1962) Intracellular and extracellular responses of several regions of the Mauthner cell of the goldfish J Neurophysiol 25:732-771.

Furukawa T, Furshpan EJ (1963) Two inhibitory mechanisms in the Mauthner neurons of goldfish. J Neurophysiol 26:140-176.

Hatta K, Korn H (1999) Tonic inhibition alternates in paired neurons that set direction of fish escape reaction. Proc Natl Acad Sci USA 96: $12090-12095$.

Hodgkin AL, Katz B (1949) The effect of temperature on the electrical activity of the giant axon of the squid. J Physiol (Lond) 109:240-249.
Johnson TP, Cullun AJ, Bennett AF (1998) Partitioning the effects of temperature and kinematic viscosity on the C-start performance of adult fishes. J Exp Biol 201:2045-2051.

Klee MR, Pierau FK, Faber DS (1974) Temperature effects on resting potential and spike parameters of cat motoneurons. Exp Brain Res 19:478-492.

Korn H, Faber DS, Triller A (1990) Convergence of morphological, physiological, and immunocytochemical techniques for the study of single Mauthner cells. In: Handbook of chemical neuroanatomy. Vol 8, Analysis of neuronal microcircuits and synaptic interactions. (Bjorklund A, Hokfeld T, Wouterlood FG, Vanden Pol AA, eds), pp 403-480. Amsterdam: Elsevier.

Lin J-W, Faber DS (1988a) Synaptic transmission mediated by single club endings on the goldfish Mauthner cell. I. Characteristics of electrotonic and chemical postsynaptic potentials. J Neurosci 8:1302-1312.

Lin J-W, Faber DS (1988b) Synaptic transmission mediated by single club endings on the goldfish Mauthner cell. II. Plasticity of excitatory postsynaptic potentials. J Neurosci 8:1313-1325.

Montgomery JC, MacDonald JA (1990) Effects of temperature on the nervous system: implications for behavioral performance. Am J Physiol 259:191-196.

Morel J, Neerchel N (1998) A goodness of fit for extra variation distributions with varying cluster sizes. Biometrika 80:363-371.

Neumeister H, Ripley B, Preuss T, Gilly WF (2000) Effects of temperature on escape jetting in the squid Loligo opalescens. J Exp Biol 203:547-557.

Nissanov J, Eaton RC (1989) Reticulospinal control of rapid escape turning maneuvers in fishes. Am Zool 29:103-121.

Nissanov J, Eaton RC, DiDomenico R (1990) The motor output of the Mauthner cell, a reticulospinal command neuron. Brain Res 517:88-98.

Oda Y, Kawasaki K, Morita M, Korn H, Matsui H (1998) Inhibitory longterm potentiation underlies auditory conditioning of goldfish escape behavior. Nature 394:182-185.

Popper AN, Fay RR (1993) Sound detection and processing in fish: critical review and major research questions. Brain Behav Evol 41:14-38.

Prosser CL, Nelson DO (1981) The role of nervous systems in temperature adaptation of poikilotherms. Annu Rev Physiol 43:281-300.

Temple GK, Johnston IA (1997) The thermal dependence of fast-start performance in fish. J Therm Biol 22:391-401.

Volgushev M, Vidyasagar TR, Chistiakova M, Yousef T, Eysel UT (2000) Membrane properties and spike generation in rat visual cortical cells during reversible cooling. J Physiol (Lond) 522:59-76.

Webb PW (1978a) Fast-start performance and body form in seven species of teleost fish. J Exp Biol 74:211-226.

Webb PW (1978b) Temperature effects on acceleration of rainbow trout Salmo gairdneri. J Fish Res Bd Can 35:1417-1422.

Webb PW (1981) Responses to northern anchovy, Engraulis mordax, larvae to predation by a biting planktivore, Amphiprion percula. Fish Bull 79:727-735.

Webb PW (1986) Effect of body form and response threshold on the vulnerability of four species of teleost prey attacked by largemouth bass (Micropterus salmoides). Can J Fish Aquat Sci 43:763-771.

Webb PW, Zhang H (1994) The relationship between responsiveness and elusiveness of heat-shocked goldfish (Carassius auratus) to attacks by rainbow trout (Oncorhynchus mykiss). Can J Zool 72:423-426.

Winter C (1973) The influence of temperature on membrane processes. In: Effects of temperature on ectothermic organisms (Wieser W, ed), pp 45-53. New York: Springer.

Yocom TG, Edsall TA (1974) Effects of acclimation temperature and heat shock on vulnerability of fry of lake whitefish (Coregonus clupeaformis) to predation. J Fish Res Bd Can 31:1503-1506.

Zottoli SJ (1977) Correlation of the startle reflex and Mauthner cell auditory responses in unrestrained goldfish. J Exp Biol 66:243-254.

Zottoli SJ, Faber DS (1980) An identifiable class of statoacoustic interneurons with bilateral projections in the goldfish medulla. Neuroscience 5:1287-1302.

Zottoli SJ, Faber DS (2000) The Mauthner cell: what has it taught us? Neuroscientist 6:26-38.

Zottoli SJ, Newman BC, Rieff HI, Winters DC (1999) Decrease in occurrence of fast startle responses after selective Mauthner cell ablation in goldfish (Carassius auratus). J Comp Physiol [A] 184:207-218. 